\title{
Changes of Residual Stresses in Austempered Spheroidal Graphite Cast Irons due to Cyclic Stress
}

\author{
Hisakichi SUNADA \\ Himeji Institute of Technology, Shosha, Himeji, Hyogo-ken, 671-22 Japan.
}

(Received on March 18, 1992; accepted in final form on September 18, 1992)

\begin{abstract}
The austempering treatment for spheroidal graphite cast iron is to produce a residual compressive stress at the surface of specimen and some retained austenite corresponding to the austempering temperature. This study was carried out to investigate the effect of the residual stress and the retained austenite on the fatigue behavior. The degree of the residual stress relaxation due to cyclic load which varies with the applied stress ratio $\left(\sigma_{\max } / \sigma_{B}, \sigma_{\max }=\right.$ cyclic max. stress, $\sigma_{B}=$ tensile strength): at the higher stress ratio the change of the residual stress is dominated at the first loading. At the lower one the extent of the relaxation of residual stress depends on the magnitude of cyclic load and the number of cycles. While the amount of the retained austenite decreases progressively during fatigue process regardless of the applied stress ratio.

These results suggest that a measurement of the residual stress and/or the retained austenite is available to predict the degree of the fatigue damage for spheroidal graphite cast iron.
\end{abstract}

KEY WORDS: austempered spheroidal graphite cast iron; fatigue; residual stress; retained austenite.

\section{Introduction}

In recent years austempered spheroidal graphite cast iron without other alloying elements has been a subject of much attention for its mechanical properties, because of its high performance of characteristic, such as high strength, ductility, toughness, ${ }^{1,2)}$ wear resistance ${ }^{3)}$ and so on. As far as concerning fatigue process, a number of investigators mainly focused on the fatigue crack propagation properties of austempered graphite cast iron. ${ }^{4 \sim 7)}$ But these reports have been limited to the fatigue crack propagation process. In the case of austempering treatment, a residual stress is introduced into the surface layer of specimen together with a retained austenite. For example, a compressive stress which is introduced by shot peening is well known to relieve as a number of fatigue cycles increases. ${ }^{8)}$ Likewise, an austenite phase in unstable stainless steel will continually transform into martensite phase during fatigue cycles applied. ${ }^{9)}$ However, the comprehensive efforts of residual stress and retained austenite in spheroidal graphite cast iron have clarified little.

In the view of practical design purpose, it is more helpful to clarify the relationships between fatigue damage and change of the amount of retained austenite or the magnitude of residual stress. The present study has been undertaken to investigate the influence of austempering treatment on the fatigue behavior of two kinds of spheroidal graphite cast irons with a ferritic matrix and a pearlitic one.

\section{Experimental Method}

The two kinds of materials used in this study were as-cast spheroidal graphite cast irons with ferritic matrix and with pearlitic one. The chemical composition of each material is given in Table 1. Materials were taken in the form of plate from Y-block casting.

Both materials were austenitized at $1173 \mathrm{~K}$ for $7.2 \mathrm{ks}$ and then quenched into a salt bath which temperature varied in the range from $573 \mathrm{~K}$ to $673 \mathrm{~K}$. The specimen was kept in the bath for $7.2 \mathrm{ks}$. Following the austempering treatment, they were cooled to room temperature in air. The structures of both materials before and after austempered at $648 \mathrm{~K}$, are shown in Fig. 1. In the figure austempered structures consist of bainitic lath and graphite nodules. But the lath spacing is rather coarser in the ferritic matrix than in the pearlitic one.

After the austempering treatment the fatigue specimens were machined by grinding work as shown in Fig. 2. Hereafter the specimen of the ferritic matrix and pearlitic one are abbreviated to simply as F-specimen and P-specimen, respectively.

In this study fatigue test was performed under load controlled condition in air at room temperature by closed

Table 1. Chemical composition of F- and P-specimens. (mass\%)

\begin{tabular}{ccccccc}
\hline & $\mathrm{C}$ & $\mathrm{Si}$ & $\mathrm{Mn}$ & $\mathrm{P}$ & $\mathrm{S}$ & $\mathrm{Mg}$ \\
\hline $\mathrm{F}$ & 3.76 & 2.21 & 0.19 & 0.017 & 0.016 & 0.038 \\
$\mathrm{P}$ & 3.70 & 2.13 & 0.34 & 0.013 & 0.008 & 0.038 \\
\hline
\end{tabular}



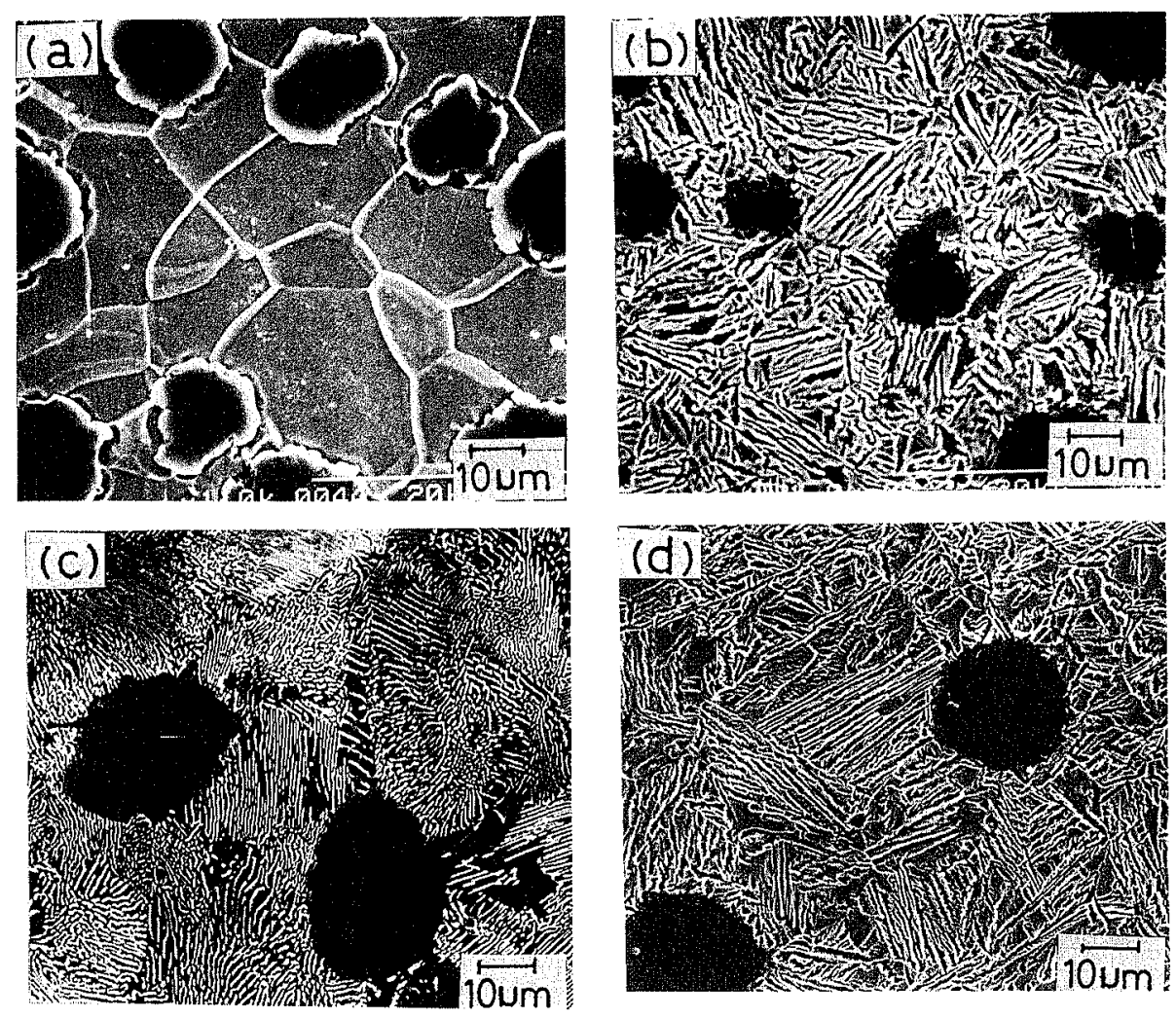

Fig. 1.

Microstructures of specimens

(a) as-cast of F-specimen

(b) austempered at $648 \mathrm{~K}$ of (a)

(c) as-cast of P-specimen

(d) austempered at $648 \mathrm{~K}$ of (c)

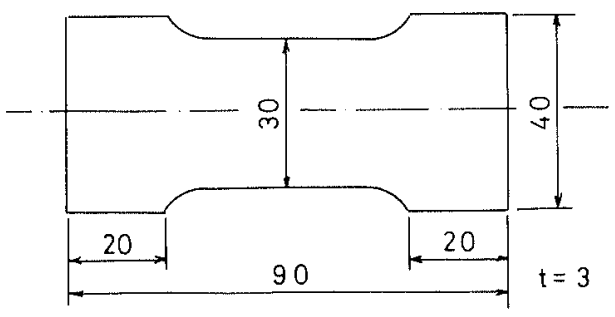

Fig. 2. Dimensions of test specimen.

loop servo-hydraulic machine using $30 \mathrm{~Hz}$ sinusoidal load. The maximum stresses were 360,228 and $163 \mathrm{MPa}$ and the load ratio, $R$, was 0.1 .

Measurement of residual stress in the surface region of the austempered specimen was done by $\sin ^{2} \psi$ technique ${ }^{10)}$ using X-ray diffraction from (211) planes at incident beam angles $0,15,30$ and 40 degrees from the normal of specimen surface. The equipment used was an automated Rigaku MSF using $\mathrm{Cr}-\mathrm{K} \alpha$ radiation $(30 \mathrm{kV}$, $10 \mathrm{~mA}$ ) filtered with vanadium foil.

Retained austenite analysis was performed with Rigaku RAD-2C diffractometer with $\mathrm{Mo}-\mathrm{K} \alpha$ radiation $(40 \mathrm{kV}, 50 \mathrm{~mA})$ for Bragg peaks (220) and (311) for austenite phase, and (200) and (211) for ferrite one.

\section{Results and Discussion}

The relations between tensile strength, yield strength, Vicker's hardness and amount of retained austenite are shown as a function of the austempering temperature in Fig. 3. As for as-cast condition, tensile strength $\sigma_{B}$, yield strength $\sigma_{Y}$ and hardness HV of P-specimen are higher than that of F-specimen. This tendency is not changed by austemper. However, mechanical properties are improved by the treatment. In the austempered

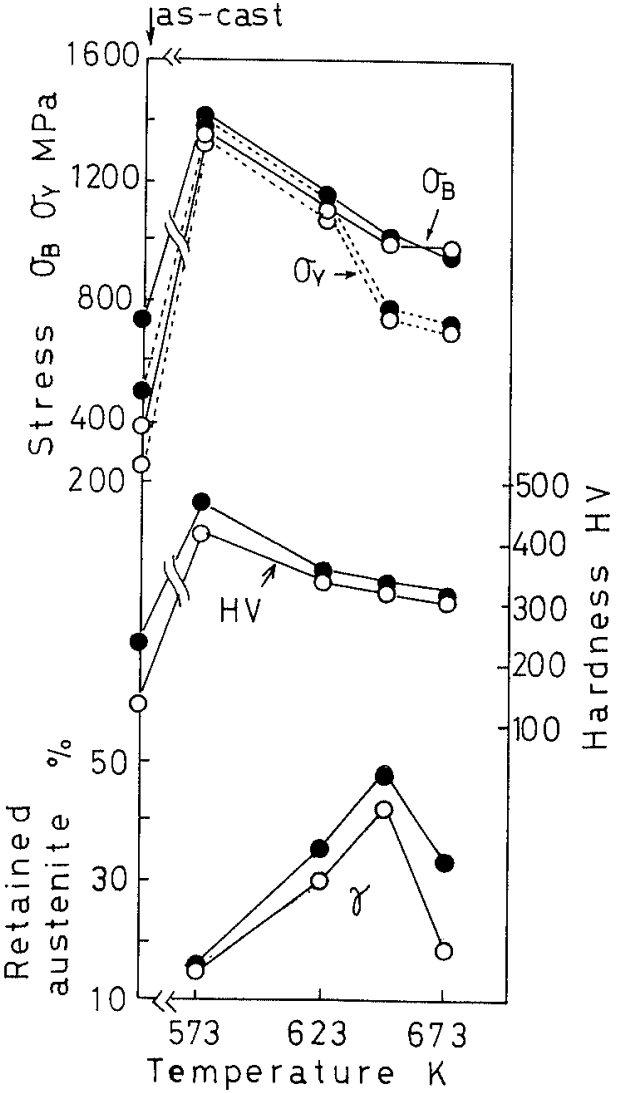

Fig. 3. The relations between tensile and yield strength, hardness and amount of retained austenite were shown as a function of austempering temperature. Solid and open circles indicate the results of F-and P-specimens, respectively.

F-specimen, these values $\left(\sigma_{B}, \sigma_{Y}, \mathrm{HV}\right)$ were improved from $392,277 \mathrm{MPa}$ and $\mathrm{HV} 145$ to in the range of 980 to $1375 \mathrm{MPa}, 751$ to $1306 \mathrm{MPa}$ and HV 313 to HV 422, 
Austempered temperature

$\oplus$ as-cast O $573 \mathrm{~K}$ ○623K $0648 \mathrm{~K}$ - $673 \mathrm{~K}$

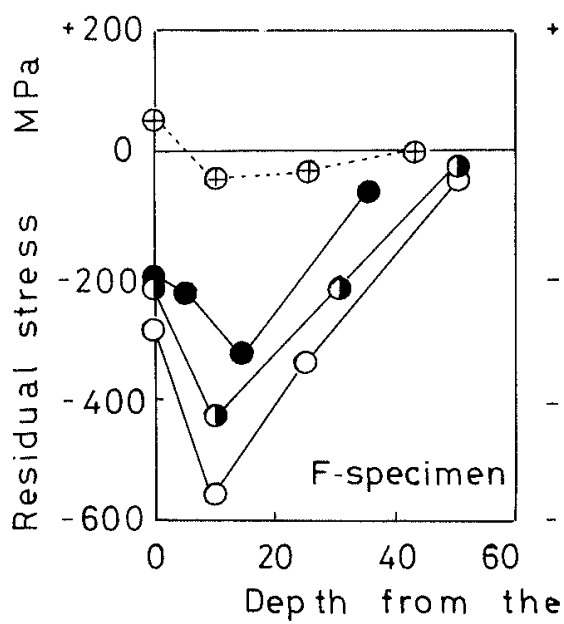

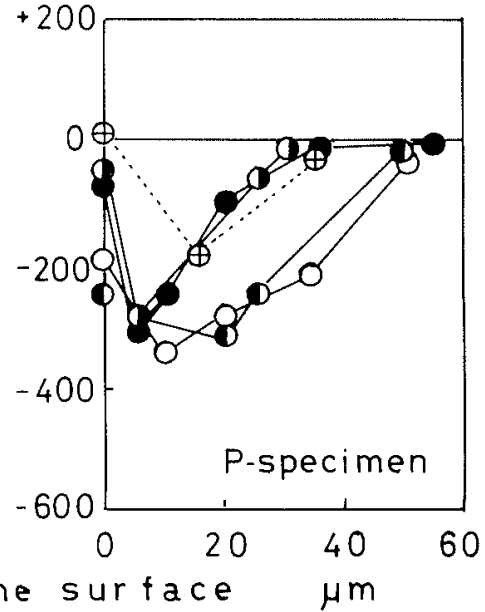

Fig. 4.

Residual stress distribution from surface in austempered specimen. respectively. The values decrease with increasing the austempering temperature.

But the amount of retained austenite increases with increasing the austempering temperature up to $40 \%$ at $648 \mathrm{~K}$ and then decreases. It seems that the retained austenite does not directly attribute to the improving of the tensile strength and the hardness. The same tendencies in the P-specimen are observed in the F-specimen. And the differences of these values between in F-specimen and in $\mathrm{P}$-one are small in the each austempered condition.

It is said that fatigue strength is generally improved when compressive residual stress presents in the surface layer. The residual stress distribution of the surface region due to the austempering treatment was measured repeatedly by removing the surface layer for an arbitary thickness by electrolytic polishing. The as-measured residual stress profiles to a depth of $50 \mu \mathrm{m}$ are shown in Fig. 4 for the different austempering temperatures. These values do not be taken account of the stress relief due to the surface removal. In both of the as-cast F- and P-specimen the residual stress in the closed area of the surface was small. The stress was probably introduced by the specimen preparation process, i.e. grinding work.

In comparison with the results of the as-cast specimen, the residual stress in austempered one increases a compressive stress about $10 \mu \mathrm{m}$ then decreases to 0 at about $50 \mu \mathrm{m}$ depth. Both materials exhibit a similar residual stress profiles. The compressive residual stress is also effected by austempered treatment, and it decrease with increasing the austempering temperature up to $648 \mathrm{~K}$. And then the value decrease with increasing the temperature. It was found that a magnitude of compressive stress is much larger in the F-specimen than in the P-specimen. The maximum value of the stress was observed at about $10 \mu \mathrm{m}$ depth and was over $500 \mathrm{MPa}$. However, the magnitude of residual stress introduced by grinding work was much smaller than the stress due to the austempered treatment. Therefore, the fatigue test was carried out using the specimen with grinding work layer.

It is well known as mentioned above that a compressive residual stress on the surface area induced by shot
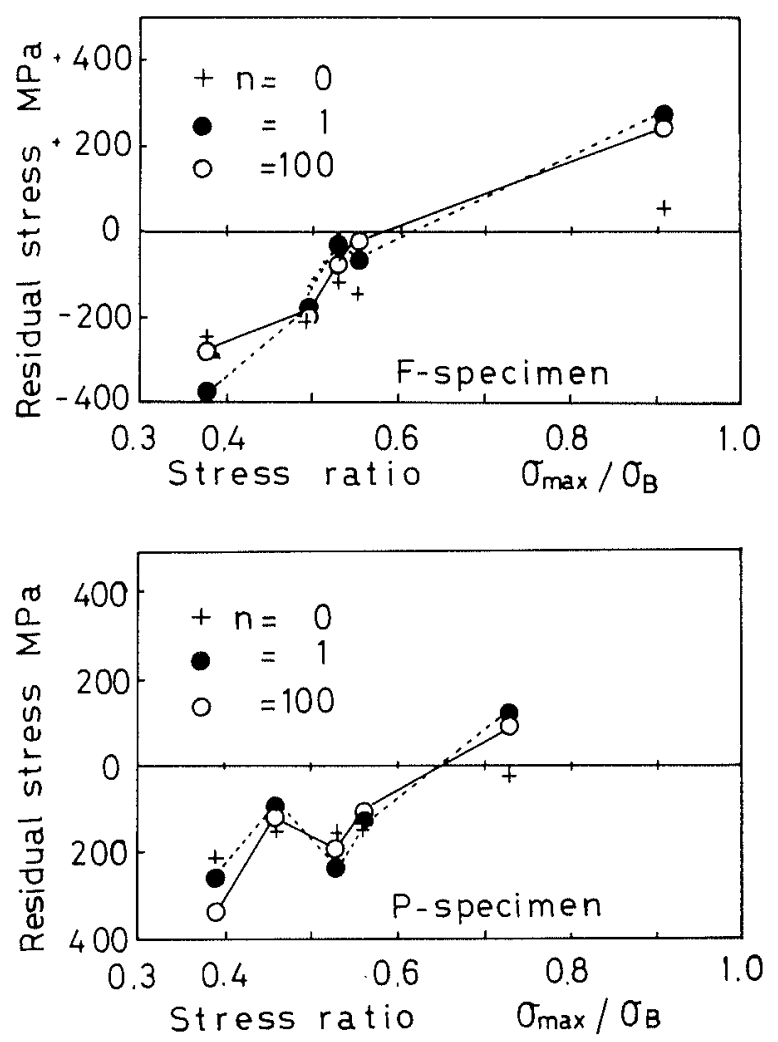

Fig. 5. Change in residual stress as a function of applied stress ratio before and after applied $l$ and 100 loading cycles.
(a) F-specimen
(b) P-specimen

peening is decayed by cyclic load. So, in order to confirm whether the residual stress on the surface is changed by the magnitude and number of cyclic loading or not, a maximum cyclic stress of $\sigma_{\max }=550 \mathrm{MPa}(R=0.1)$ was applied on the specimen for 1 and 100 cycles regardless on the structure or the tensile strength. The measured residual stresses are plotted as ordinate against the applied stress ratio $\left(\sigma_{\max } / \sigma_{B}, \sigma_{B}\right.$ is tensile strength in Fig. 3 ) as abscissa, as shown in Fig. 5. A trend may be noted from these plots: at high load ratio the residual stress was dismissed and further increased to the yield strength in case F-specimen $\left(\sigma_{\max } / \sigma_{B}=0.92\right)$. On the other hand the compressive residual stress increases furthermore at 

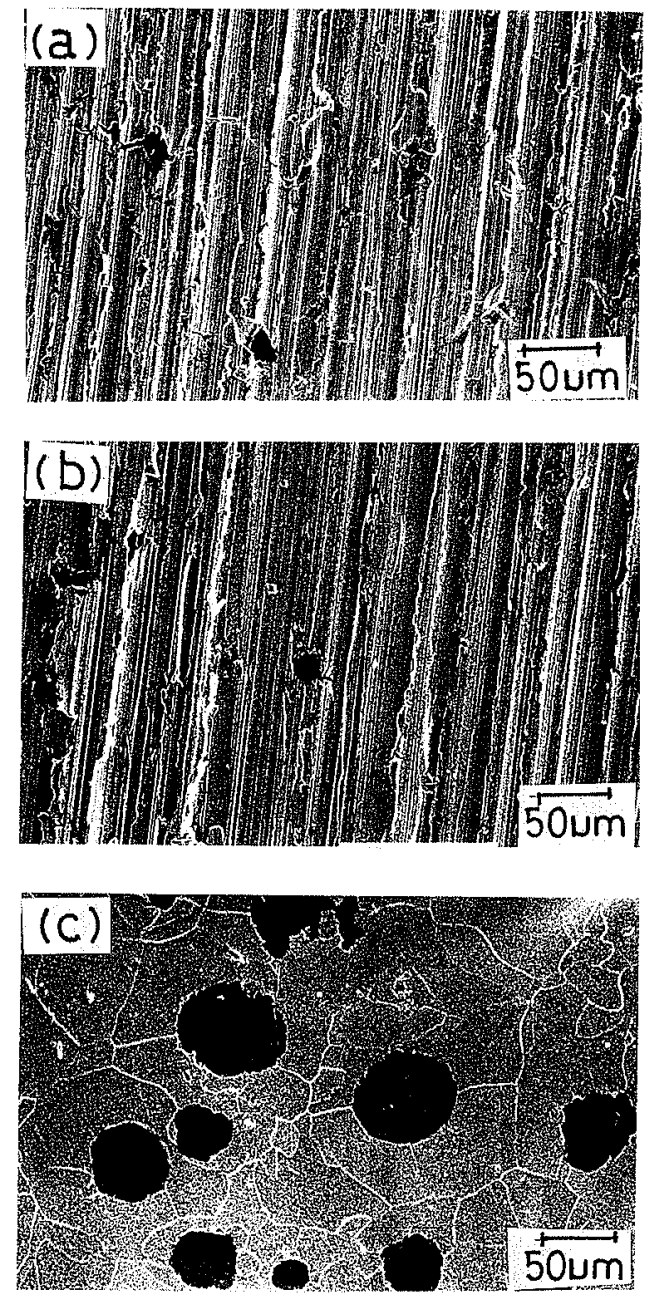

Fig. 6. Scanning micrograph of F-specimen showing surface crack initiation after applied 100 load cycles.

(a) unaustemper treatment

(b) bainite structure austempered at $648 \mathrm{~K}$

(c) $0.1 \mathrm{~mm}$ removed the surface of (a) and chemical etched by $5 \%$ nital

stress ratio 0.38 . It can be also seen that the change of the residual stress by cyclic loading is mainly dominated at the start of the loading condition.

Scanning electron microscopy of the as-cast Fspecimen surface after 100 cycle loading in Fig. 6(a) revealed a numerous small fatigue crack. But Fig. 6(b) shows that it is difficult to detect the fatigue cracks on the surface of the austempered specimen at $648 \mathrm{~K}$. The results of this observation indicate that the applied stress value or plastic strain relates to relaxation of the residual stress and leads to decay the residual stress in surface layer. When the surface layer of Fig. 6(a) was removed $0.1 \mathrm{~mm}$ away by chemical etching, the fatigue cracks disappeared as shown in Fig. 6(c). This evidence suggests that the fatigue damage phenomenon in this study is limited only in the surface layer.

Austempered cast iron generally consists of a mixture of two phases (i.e., bainitic ferrite and retained austenite). If the retained austenite is unstable, the phase transforms into martensite by the applied strain as unstable stainless steel. A measurement of the amount of the retained austenite was performed by X-ray using the integrated

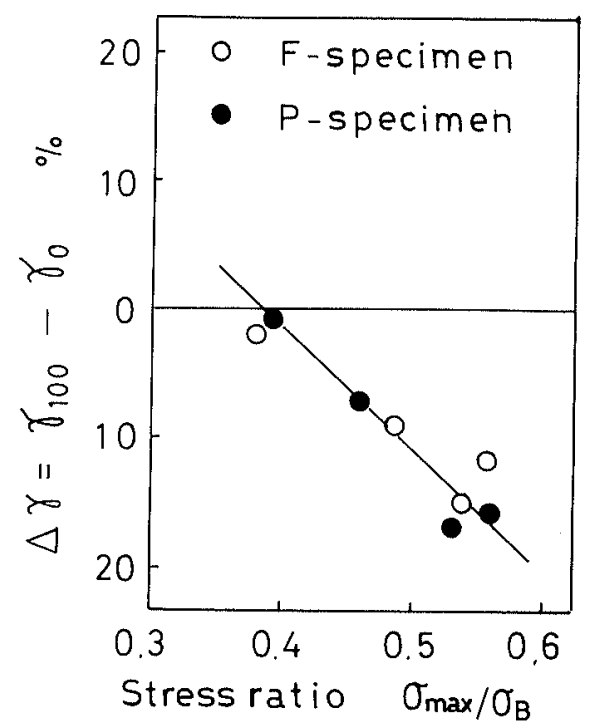

Fig. 7. Change the amount of retained austenite, $\Delta \gamma$, as a function of applied stress ratio before and after applied 100 load cycles.

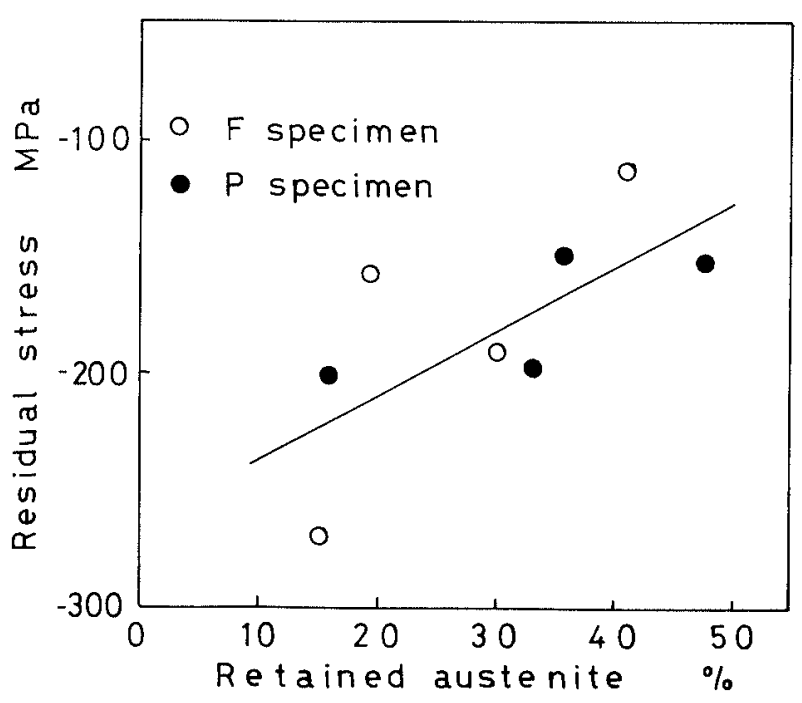

Fig. 8. Comparison of the amount of retained austenite and the residual stress on the surface after 100 times of cyclic loading.

intensities of diffraction of (220) and (311) of austenite phase and of (200) and (211) of ferrite phase. In Fig. 7 the amount of the retained austenite, after maximum cyclic stress $\sigma_{\max }=550 \mathrm{MPa}$ was applied for 100 cycles, is plotted as a function of the stress ratio $\left(\sigma_{\max } / \sigma_{B}\right)$ in a similar way in Fig. 5. It can be seen that the amount of the retained austenite decreased with increasing the load ratio during fatigue process.

The values of the residual stress are plotted against the amount of the retained austenite in Fig. 8. The relationship between the residual stress $\sigma$ and the amount of the retained austenite $\gamma$ can be expressed by the formula:

$$
\sigma(\mathrm{MPa})=2.7 \gamma(\%)-261
$$

which is shown as the line in Fig. 8. As can be seen the scatter in the data is very large, that is, the correlation coefficient, $r$, is 0.70 . It is difficult to obtain the precise 

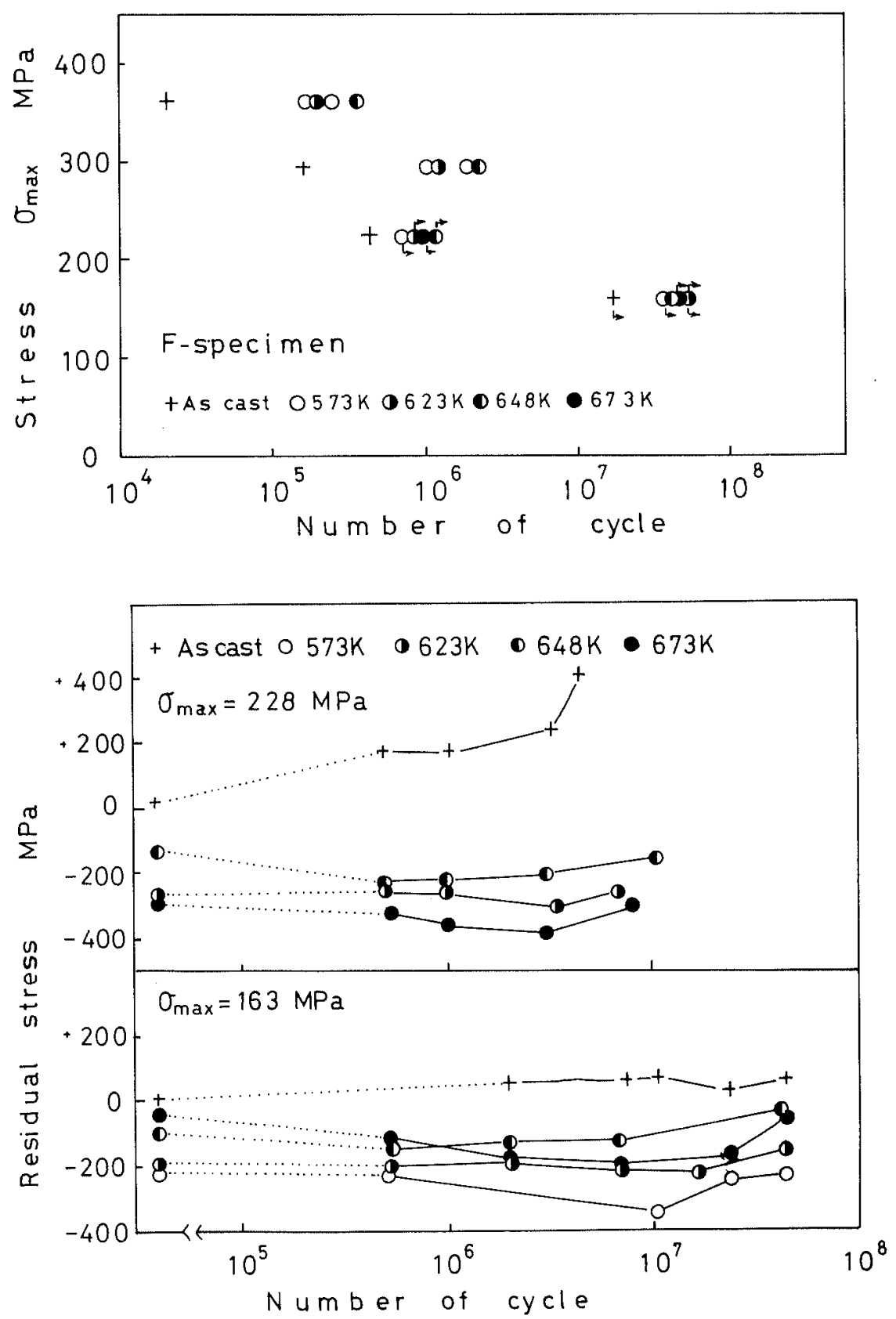

Fig. 9.

Relation between $\sigma_{\max }$ and fatigue life. The effects of austempered temperature are also shown.
Fig. 10.

Variation of residual stress of F-specimen as a function of the applied number of cycles. relationship from the present results. However, the results clearly show that the magnitude of residual stress is closely related to the amount of retained austenite.

Plots for maximum applied stress vs. number of cycles in this fatigue test for F-specimen, so called $\mathrm{S}-\mathrm{N}$ curves, are shown in Fig. 9. Though the number of the tested specimen is limited, these plots for the austempered specimens shift to the right region. From these results the fatigue life is improved by the austempering treatment as well as the yield strength.

Next, to examine further an effect of number of cyclic loading on the variation of the residual stress, fatigue test at maximum cyclic stress $\sigma_{\max }=228$ and $163 \mathrm{MPa}$ for F-specimen were carried out. The results are shown in Fig. 10. In the case of the as-cast specimen (mark + ), the residual stress produced progressively with increasing the number of cycles at high stress $\sigma_{\max }=228 \mathrm{MPa}$ and reached its yield strength, whereas at lower stress, $\sigma_{\max }=163 \mathrm{MPa}$, there was very little variation in excess of $n=4 \times 10^{7}$. On the other hand, the compressive residual stress of the austempered specimen increased somewhat as the number of cycles increased regardless of the austempering temperature. After that the values set to decrease to positive stress. Taira and Honda ${ }^{11)}$ have demonstrated that compressive internal stress in the early stage of alternating stressing is generated on the surface by the extrusion and intrusion phenomena. The slip would result in microcracks (in Fig. 6), and the microcracks make relax the compressive residual stress.

To examine the change in the residual stress of F-specimen during fatigue process, the test results are plotted in Fig. 11(a), assuming the residual stress is as a function of the stress ratio $S\left(=\sigma_{\max } / \sigma_{B}\right)$ and the fatigue damage $D\left(=n / N_{f}, n\right.$ and $N_{f}$ are the number of cycles applied and the fatigue life at the same cyclic stress). The method is as follows: First, Basquin's equation ${ }^{12)}$ $\left(\sigma_{\max } N_{f}^{m}=C, m\right.$ and $C$ are coefficient) leads from the fatigue test results in Fig. 9. Then the apparent fatigue 

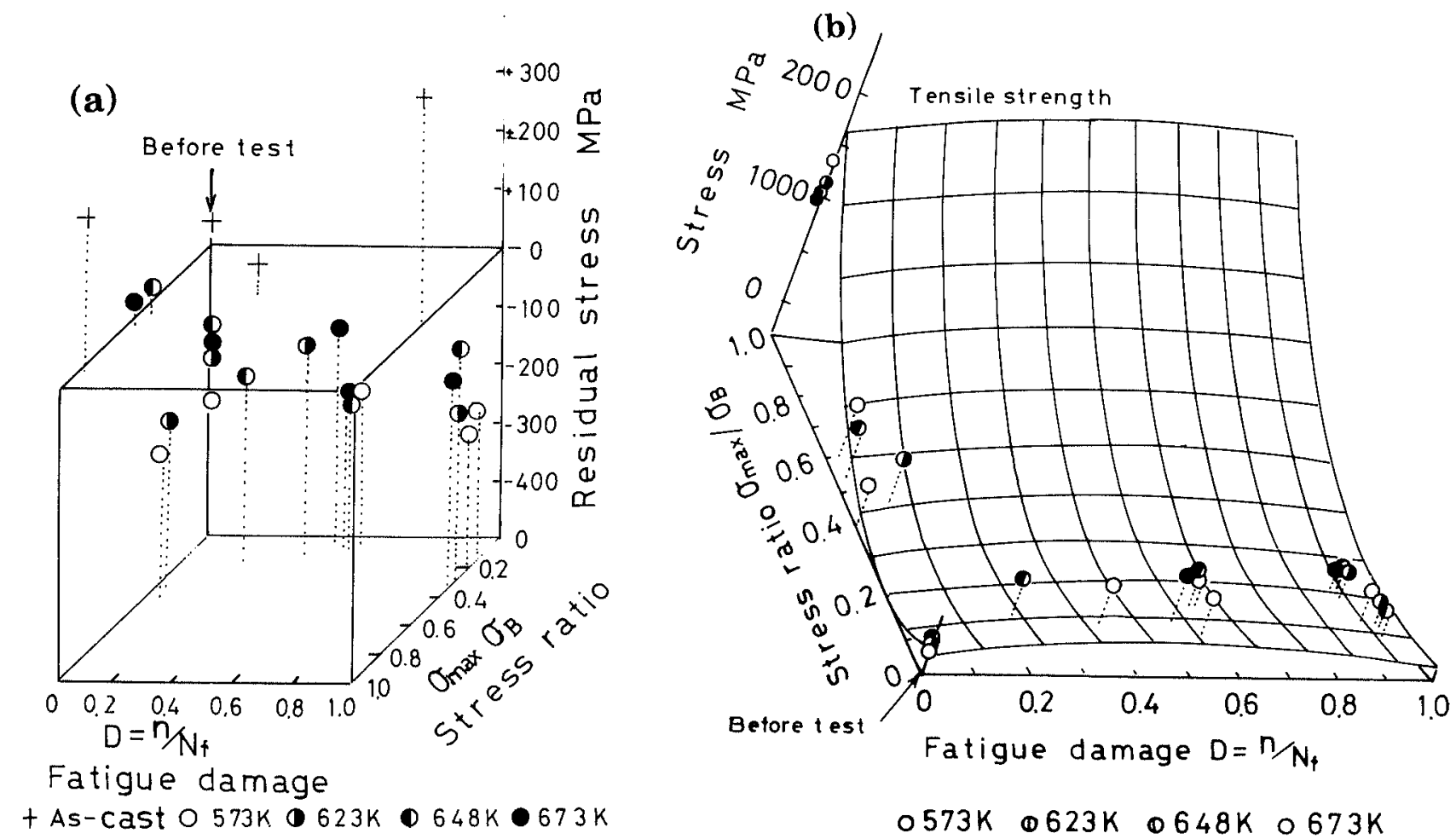

Fig. 11. Change of residual stress in dependence of fatigue damage and stress ratio of $F$-specimen.
(a) test results
(b) test results of austempered specimen

life $N_{f}$ at $\sigma_{\max }=550,228$ and $163 \mathrm{MPa}$ determine in order to estimate the fatigue damage $D=n / N_{f}$ in the light of modified Miner's law. A trend on as-cast F-specimen can be seen in Fig. 11(a). The tensile residual stress (mark + ) causes with increase the fatigue damage ratio $D$ and the stress ratio $S$. But it is difficult for them to find some tendency directly from the figure in austempered specimen. Therefore, in order to find the tendency it is assumed that the all the data are one curved suface which is formed by the following equation:

$$
\sigma(D, S)=a+b D+c S+d D^{2}+e S^{2}+f D S
$$

where $a, b, c, d, e$ and $f$ are coefficients, $D$ and $S$ is fatigue damage and stress ratio, respectively. These coefficients were obtained by a least squares method. The change of the residual stress are calculated against each $D$ and $S$ at interval of 0.1 , respectively. A curved surface such as a Fig. 11(b) is drawn by plotting these values $\sigma(D, S)$. The curved surface is shown in Fig. 11(b) suggests that the compressive residual stress is lost by simply tensile deformation: there is appreciable decay of the residual stress after first cycle. Moreover, the values changes into a cyclic stressing: a significant decay of the residual stress occures up to or over the tensile strength.

Figure 12 shows that a transformation take gradually place during the fatigue process as well as the behavior of the residual stress.

It can be concluded that a tendency, to decay the compressive residual stress on the surface to tensile one and to transform to martensite phase of the retained austenite through fatigue process, can avairable to predict the service life of the austempered spheroidal graphite cast iron. But further study will be required on a contribution of the metallographical study to confirm a

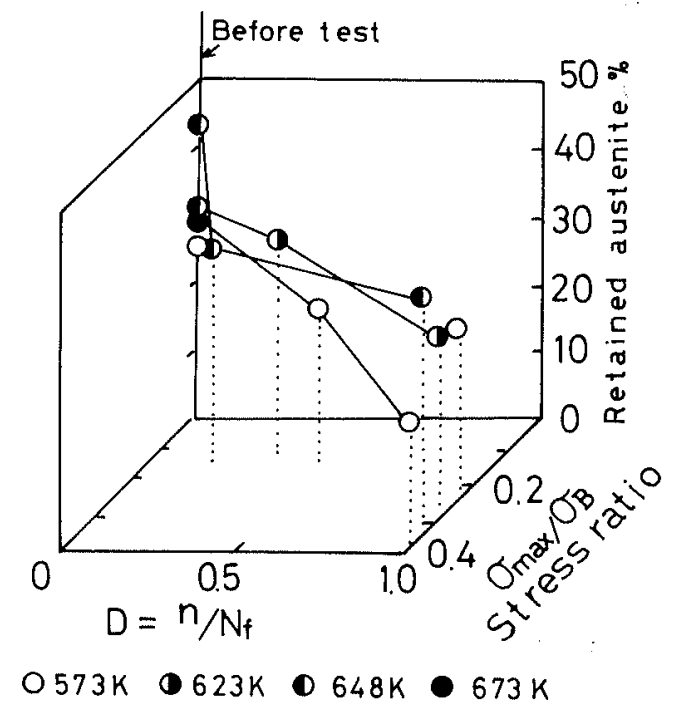

Fig. 12. Change of retained austenite dependence on fatigue damage and stress ratio of F-specimen.

relationship between the retained austenite and the residual stress during fatigue process.

\section{Conclusion}

The effect of the retained austenite and the residual stress in the surface of specimen which is produced by austempering treatment on fatigue behavior was investigated. Two kinds of spheroidal graphite cast irons, ferritic matrix and pearlitic one, were used. The obtained results are summarized as follows:

(1) The effect of austempering treatment is to produce a residual compressive stress in the surface area of specimen together with a retained austenite. These values 
depended on the austempering temperature.

(2) At high cyclic stress region the relaxation of the residual compressive stress occurred in the early stage of fatigue process. The maximum values of the residual stress increased closed to the tensile yield strength finally of which of as-cast ferrite strcture. At lower cyclic loading the magnitude of the compressive stress increased once in the early fatigue process and then decreased the value.

(3) The amount of the retained austenite decreased progressively with increasing the number of stress cycles regardless of magnitude of applied stress.

The above results may indicate that the measurent of the residual stress or the retained austenite in service is available to predict the degree of the fatigue damage.

\section{Acknowledgments}

The author wishes to thank Hitachi Metals, Ltd. for the supply of the test materials. The auther would also like to express gratitude to Rigaku Ltd. for the measuring of the retained austenite.

\section{REFERENCES}

1) Metal Handbook, Vol. 8, ed. by ASM, N.Y., (1985), 375.

2) K. Nagai, K. Kishitake and T. Owadano: Mat. Sci. Tech., 7 (1991), 468.

3) S. Skepperson and C. Allen: Wear, 121 (1988), 271.

4) M. Johansson: Trans. AFS., 85 (1977), 117.

5) F. D. Griswold and R. I. Stephens: Int. J. Fatigue, 9 (1987), 3.

6) J. Dong and S. Yu: Int. J. Fatigue, 12 (1990), 481.

7) J. Hwang, C. Perg and Y. Shan: Int. J. Fatigue, 12 (1990), 481.

8) J. D. Almen and P. H. Slach: Residual Stress and Fatigue in Metals, McGraw-Hill, N.Y., (1963), 78.

9) D. Hennessy, G. Steckel and C. Altstetter: Metall. Trans., 7A (1976), 415 .

10) Metal Handbook, Vol. 10, ed. by ASM, Ohio, (1986), 380.

11) S. Taira and K. Honda: Proc. Ist Conf. on Fracture, Vol. 3, (1965), 1581.

12) H. O. Fuchs and R. I. Stephens: Metal Fatigue in Engineering, John Wiley \& Sons, N.Y., (1980), 78. 